\title{
The Impact of Nutrition on the Development and Prognosis of Breast Cancer
}

\author{
Hans Hauner Dagmar Hauner \\ Else Kröner-Fresenius-Center for Nutritional Medicine, Technische Universität München, Germany
}

\section{Keywords}

Breast cancer: development, survival/prognosis, mortality - Diet - Obesity

\section{Summary}

Breast cancer is the most frequent type of cancer in women. Recent data suggest that lifestyle factors including dietary factors play a significant role in the development of and survival from breast cancer. In particular, there is convincing evidence that obesity is a potent risk factor for both cancer development and prognosis, increasing the risk for overall and breast cancer mortality by approximately $30 \%$. In contrast, there is still only limited evidence that specific dietary patterns or dietary components affect breast cancer outcomes. However, current knowledge suggests that a healthy/Mediterranean-like diet characterized by high intake of fruit, vegetables, fiber, fish and unsaturated oils, particularly n-3 fatty acids, has a modest protective effect on breast cancer, whereas a typical Western diet characterized by high intake of total/saturated fat, refined carbohydrates, processed and red meat and low fiber intake is associated with modestly poorer outcome. Based on this evidence, weight control is a key recommendation for primary and secondary prevention of breast cancer. Adherence to a healthy/Mediterranean-like diet and avoidance of a Western diet may confer additional, although still unproven, benefit.

\section{Introduction}

Breast cancer is the most common type of cancer in women worldwide. Over 1 million incident cases were recorded in 2002 , accounting for around $23 \%$ of all cancers in women [1]. According to population-based registries, almost 58,000 new

\section{Schlüsselwörter}

Brustkrebs: Entwicklung, Überleben/Prognose, Mortalität . Ernährung · Adipositas

\section{Zusammenfassung}

Das Mammakarzinom ist die häufigste Tumorerkrankung bei der Frau. Neuere Studienergebnisse legen nahe, dass Lebensstilfaktoren und dabei insbesondere die Ernährung eine signifikante Bedeutung für die Entstehung und Prognose des Mammakarzinoms besitzen. Es gibt überzeugende Evidenz, dass Adipositas ein wichtiger Risikofaktor sowohl für die Inzidenz als auch für die Prognose der Erkrankung ist und dabei die Gesamt- und brustkrebsspezifische Mortalität um annähernd 30\% erhöht. Im Gegensatz dazu liegt nur begrenzte Evidenz vor, dass bestimmte Ernährungsmuster und einzelne Ernährungskomponenten Brustkrebsrelevante Endpunkte beeinflussen. Nach der derzeitigen Datenlage hat eine gesunde, der Mittelmeerkost entsprechende Ernährung mit einem hohen Verzehr von Obst, Gemüse, Vollkornprodukten, Fisch und ungesättigten Fetten, insbesondere omega-3-Fettsäuren, eine mäßige Schutzwirkung, während eine typisch westliche Ernährung mit hoher Zufuhr von gesättigten Fetten, rasch resorbierbaren Kohlenhydraten, rotem Fleisch und Fleischprodukten sowie wenig Ballaststoffen mit einer schlechteren Prognose assoziiert ist. Vor diesem Hintergrund stellt die Gewichtskontrolle eine entscheidende Empfehlung für die Primärund Sekundärprävention von Brustkrebs dar. Die Einhaltung einer gesunden, ausgewogenen Kost scheint einen zusätzlichen, wenngleich noch nicht ausreichend belegten Nutzen zu haben.

cases are documented in Germany annually, and 17,000 were reported to have died from breast cancer in 2006. Furthermore, these registries also indicate that between 83 and $87 \%$ of women with newly diagnosed breast cancer survive the first 5 years after diagnosis [2].

\begin{tabular}{ll}
\hline KARGER & ๑ 2010 S. Karger GmbH, Freiburg \\
Fax +497614520714 & Accessible online at: \\
Information@Karger.de & www.karger.com/brc \\
www.karger.com &
\end{tabular}

Prof. Dr. Hans Hauner

Else Kröner-Fresenius-Zentrum für Ernährungsmedizin der TU München

Gregor-Mendel-Str. 2, 85350 Freising-Weihenstephan, Germany

Tel. +49 8161 71-2000, Fax -2097

hauner@wzw.tum.de 
Over the last years, there was growing interest in the effects of lifestyle factors related to diet and physical activity on the development of breast cancer as well as on breast cancer survival. This interest was also raised by the recent report of the World Cancer Research Fund (WCRF) on primary prevention of cancer in general. This report presents the results of a comprehensive analysis of the modifiable causes of cancer related to lifestyle, also including a careful weighing of the evidence according to predefined criteria. Concerning breast cancer, it was concluded that there is convincing evidence that alcoholic drinks increase the risk of both pre- and postmenopausal breast cancer. Obesity or body fatness was found to be a strong risk factor for postmenopausal breast cancer, whereas an inverse relationship was observed between body mass index (BMI) and premenopausal breast cancer estimated as probable evidence. Adult weight gain was identified as another risk factor that promotes postmenopausal breast cancer with probable evidence. Among the diets and dietary components under review, only total fat intake was identified as risk factor for postmenopausal breast cancer supported by limited/ suggestive evidence [1].

Since this report was published there has been a rapidly growing amount of literature on the role of lifestyle factors in breast cancer development and survival. In this review, only nutritional and body weight aspects are covered, although physical activity may be of similar importance [3]. It is noteworthy that recent publications considerably expanded our knowledge on these associations and have been carefully reviewed. Therefore, this article is particularly dealing with new literature on this topic and will address current developments in the field.

\section{Dietary Factors Affecting the Development of Breast Cancer}

The diet of an individual or of a specific group/population represents a complex phenomenon that may vary day by day and may change markedly over longer periods. It should also be noted that our instruments to measure dietary intake and our methods to analyze dietary records are subject to substantial confounding and errors and, thus, may provide only crude information. In view of these limitations, it may be more reasonable and reliable to consider data on dietary patterns rather than focusing on single food components or ingredients.

\section{Dietary Patterns and Risk of Breast Cancer}

In a recent meta-analysis, Brennan et al. [4] searched for all relevant literature to identify common dietary patterns and their relation to breast cancer risk. They divided the identified studies into those with a prudent/healthy dietary pattern $(\mathrm{n}=18)$, those with a Western/unhealthy pattern $(\mathrm{n}=17)$, and those with a drinker dietary pattern $(n=4)$. The risk of breast cancer was decreased in the highest compared to the lowest categories of prudent/healthy dietary patterns (odds ratio (OR), 0.89; 95\% confidence interval (CI): 0.82-0.99, $\mathrm{p}=0.02)$ in all studies. There was no evidence of a difference in risk of breast cancer between the highest and the lowest categories of Western/unhealthy dietary patterns (OR, 1.09; 95\% CI: $0.98-1.22, p=0.12$ ). An increase in the risk of breast cancer was found for the highest compared to the lowest categories of drinker dietary patterns (OR, 1.21; 95\% CI: $1.04-1.41, \mathrm{p}=0.01$ ), indicating that specific dietary patterns are associated with decreased or increased risk of breast cancer [4].

In a recent analysis of the Greek EPIC cohort $(\mathrm{EPIC}=$ European Prospective Investigation into Cancer and Nutrition), conformity to a traditional Mediterranean diet was shown to be weakly associated with lower breast cancer risk among postmenopausal women, and could explain, in part, the lower incidence of this disease in Mediterranean countries [5]. In a large French cohort study including 65,374 women with 2381 postmenopausal invasive breast cancer cases (after a median follow-up period of 9.7 years, from 1993 to 2005), 2 relevant dietary patterns related to breast cancer risk were identified. An alcohol/Western dietary pattern was positively associated with breast cancer risk (hazard ratio (HR), 1.20; 95\% CI: $1.03-1.38, \mathrm{p}=0.007)$, whereas the healthy/Mediterranean dietary pattern was negatively associated with breast cancer risk (HR, 0.85; 95\% CI: 0.75-0.95, p = 0.003), especially when tumors were estrogen-receptor (ER) positive [6]. These data suggest that adherence to a healthy, Mediterranean-like diet along with avoidance of Western-type foods may contribute to a substantial reduction in postmenopausal breast cancer risk.

\section{Dietary Components and Breast Cancer Risk}

Many analyses of large prospective cohort studies are now available that deal with macronutrient composition, the role of defined food groups, and the contribution of micronutrients such as vitamins and trace elements or of special supplements. Only major findings will be covered with reference to recent reviews.

The 6 prospective studies on fruit and vegetable intake that were recently analyzed did not reveal a statistically significant association with breast cancer [7]. Concerning the role of vitamins, minerals and trace elements there is no evidence from the existing literature that these micronutrients contribute to the risk of developing breast cancer, as carefully reviewed by the WCRF [1].

In a recent analysis of the VITamins And Lifestyle (VITAL) cohort, the association between long-term use of speciality supplements and breast cancer risk was assessed in 35,016 postmenopausal women who had completed a detailed questionnaire on supplement use between 2000 and 2002 . The main finding was that current use of fish oil was associated with reduced risk of incident breast cancer (HR, 0.68; 
95\% CI: 0.50-0.92). The 10-year average use was suggestive of reduced risk ( $\mathrm{p}$ for trend $=0.09$ ). The remaining speciality supplements, including products used for menopausal symptoms such as black cohosh, dong quai, soy or St. John's wort, were not associated with breast cancer risk [8]. A potential mechanism for this observation may be that long-chain $n-3$ fatty acids reduce prostaglandin E2 (PGE2) synthesis, which is known to promote de novo estrogen synthesis in breast epithelia and stroma cells, thereby contributing to carcinogenesis [9].

\section{Alcohol Consumption and Risk of Breast Cancer}

A meta-analysis of observational studies reported that postmenopausal women who drink alcohol have a $22 \%$ (95\% CI: 9-37\%) higher relative risk of breast cancer than those who do not drink alcohol. The analysis estimated that every additional $10 \mathrm{~g}$ of alcohol consumed per day (e.g. $100 \mathrm{ml}$ of wine) was associated with a $10 \%$ (95\% CI: $5-15 \%)$ increase in relative risk [10].

\section{Primary Prevention of Breast Cancer}

There is only 1 large prevention study involving a total of 48,835 postmenopausal women aged 50-79 years that investigated the effect of lowering fat intake on the incidence of invasive breast cancer in a randomized controlled trial. The results of the Women's Health Initiative indicate that a lowfat diet might reduce the relative risk of developing breast cancer by approximately $9 \%$ ( $95 \%$ CI: $-1 \%$ to $+17 \%)$ over an 8.1-year follow-up period; however, the estimated risk reduction was not statistically significant. Secondary analyses suggested a greater risk reduction among adherent women and among women having a high-fat diet at baseline [11].

\section{Dietary Factors and Prognosis of Breast Cancer}

For various reasons, breast cancer is becoming more and more a chronic disease [2]. However, this does not necessarily imply that mortality from breast cancer has changed considerably. The high survival rates of women with early stages of breast cancer may raise the awareness that any discussion on the role of lifestyle factors should include the perspective that the majority of women suffering from breast cancer are postmenopausal and at high risk of developing other chronic diseases such as cardiovascular disease or type 2 diabetes. Therefore, it is necessary to have a comprehensive look at morbidity and mortality and, finally, to distinguish between total and breast cancer-related endpoints. Thus, any lifestyle intervention program to improve the prognosis of breast cancer may also confer additional benefit caused by a concomitant reduction of risk for other chronic diseases.

\section{Dietary Pattern and Breast Cancer Survival}

To date, there is very limited information on the potential role of a specific dietary pattern in breast cancer survival. In a study by Kwan et al. [12], a prudent dietary pattern characterized by high intake of fruits, vegetables, whole grains, legumes, poultry and fish appeared to be protective (HR for highest quartile $=0.57,95 \% \mathrm{CI}: 0.36-0.90$, p for trend $=0.02$ ), whereas a Western dietary pattern characterized by high intake of refined grains, processed and red meat, desserts, highfat dairy products and fried potatoes was associated with an increased risk of mortality $(\mathrm{HR}$ for highest quartile $=1.53$, 95\% CI: $0.93-2.54$, p for trend $=0.05$ ). However, neither dietary pattern was associated with breast cancer recurrence or death from breast cancer. Similar data were previously published by another group [13].

\section{Dietary Components and Breast Cancer Survival}

At present, there are more than a dozen observational studies that investigated the effects of macronutrients on breast cancer outcomes [3]. For most of these studies the results are mixed. However, there are trends that diets high in dietary fiber content are protective and diets high in fat content increase mortality [3]. The analyses of potential associations between carbohydrate or protein intake and breast cancer mortality were inconsistent and are not further presented due to major limitations. At present, there are 7 cohort studies that report on the effect of alcohol on breast cancer outcome. The results were inconsistent, although in 3 studies a reduction of total mortality was found, possibly due to the effects of alcohol on cardiovascular mortality [3]. Concerning fruit and vegetable intake, the few cohort studies addressing this topic revealed a trend towards being protective, but are inconsistent [3].

Among the vitamins, minerals, and trace elements studied so far, single-cohort studies point to a potential beneficial effect with respect to overall and cancer-specific mortality, but the studies were generally too small and not sufficiently adjusted to allow firm conclusions $[3,14,15]$. In contrast, the use of supplemental antioxidants during chemotherapy and radiation therapy should be discouraged due to the possibility of tumor protection and reduced survival [16].

\section{Special Supplements and Breast Cancer Survival}

Soy foods are rich in isoflavones, a group of phytoestrogens hypothesized to reduce the risk of breast cancer. In a recent study from China, soy food consumption was significantly associated with decreased risk of death and recurrence among women with breast cancer [17].

Green tea is commonly consumed by breast cancer survivors due to postulated anti-inflammatory and anti-carcinogenic properties. In a recent meta-analysis of the existing literature, namely 2 cohort studies from Japan, the conclusion was that increased green tea consumption (more than 3 cups a 
day) may be inversely associated with risk of breast cancer recurrence [18].

However, definite conclusions as to the therapeutic application of soy foods and green tea are currently impossible to make, due to the small number of studies.

\section{Intervention studies}

Early suggestive data from observational studies in the 1990s resulted in the conduction of 2 large randomized, controlled intervention studies in early-stage breast cancer survivors. The Women's Intervention Nutrition Study (WINS) focused on the efficacy of a reduction of fat intake to $15 \%$ of total energy [19], whereas the Women's Healthy Eating and Living (WHEL) study focused on the efficacy of a similar reduction in fat intake and an increase in fruit, vegetable and fiber consumption [20].

Neither study reported an effect of the intervention on total mortality. The respective HR for the WIN study was $0.89(95 \% \mathrm{CI}: 0.65-1.21, \mathrm{p}=0.56)$ and for the WHEL study 0.97 (95\% CI: 0.78-1.22, p = 0.82). In addition, the HR for disease-free survival in both the WIN study (HR, 0.76, $\mathrm{p}=0.077)$ and the WHEL study (HR, 0.99, $\mathrm{p}=0.87)$ did not reach statistical significance. However, in the WIN study, subgroup analysis revealed a significant effect of the intervention in the ER/progesterone receptor-negative ( $\mathrm{PR}-$ ) subgroup, which was not confirmed in a similar subgroup analysis of the WHEL study. A subsequent analysis of the WHEL data showed the greatest intervention effect in the subgroup of the participants with the best-quality diet at baseline [21]. Another interesting difference between the 2 studies was that the women of the WIN study randomized to the low-fat intervention experienced a modest weight loss, resulting in a weight difference of $2.7 \mathrm{~kg}$ compared to the control group, whereas a parallel modest weight gain was observed in both groups of the WHEL study. Reviewing both intervention studies, one has to keep in mind that the extent of dietary changes achieved in both studies was moderate and obviously did not reach the defined targets. Furthermore, the intervention programs focused only on the amount of fat, not fat quality, as well as on fruit, vegetable and fiber intake, thereby neglecting other potentially important dietary components [3].

\section{Body Weight, Weight Gain, and Risk of Breast Cancer}

The WCRF report has clearly established that overweight/ obesity is a risk factor for the development of breast cancer [1]. In 9 prospective cohort studies with a total of 18,508 patients with breast cancer that addressed the association between change in weight and subsequent risk of breast cancer, all reported that gaining weight from younger to older ages was associated with a statistically significant increased risk of breast cancer for pre- and postmenopausal women [7].

\section{Body Weight, Weight Gain, and Breast Cancer Prognosis}

In a recent meta-analysis, 43 studies were identified that enrolled women diagnosed between 1963 and 2005. The metaanalysis showed poorer survival in obese compared with nonobese women with breast cancer, which was very similar for overall (HR, 1.33; 95\% CI: 1.21-1.47) and breast cancer-specific mortality (HR, 1.33; 95\% CI: 1.19-1.50). A similar result was obtained when the waist/hip ratio (WHR), a measure of body fat distribution, was used. Interestingly, and in contrast to the role of obesity for the incidence of breast cancer, the adverse effect of obesity on survival was slightly greater in premenopausal as compared to postmenopausal women (HR, 1.47 vs. 1.22, not significant (n.s.)) [22]. In a systematic review, there was some, but not convincing, evidence that weight gain may reduce breast cancer prognosis [3].

\section{Conclusions}

The most consistent finding from the meta-analyses performed recently is that overweight and obesity are associated with an elevated risk of developing breast cancer and a poorer prognosis of patients with newly diagnosed breast cancer. On average, obesity increased both overall and breast cancer-specific mortality by approximately $30 \%$. The pathophysiological link is not fully elucidated, but may include an increased estrogen production by adipose-tissue stromal cells, elevated levels of insulin and insulin-like growth factor (IGF)-1, a role of specific adipose tissue-derived factors ('adipokines'), and possibly other mechanisms related to an expanded fat mass [23-25].

The associations between diet or dietary components and breast cancer incidence and prognosis were weak and inconsistent, which may be not only due to sparse data but also to considerable errors in the measurement of food intake. Nevertheless, current data suggest that a healthy/Mediterranean-like diet characterized by high intake of fruit, vegetables, fiber, unsaturated fat and fish may have some protective effect against breast cancer development and adverse outcome, whereas an unhealthy/Western-style diet characterized by high saturated-fat content, low fiber, processed and red meat, and high alcohol intake has the opposite effect.

Unfortunately, there is a lack of intervention studies to further develop and substantiate the dietary concept to modify the risk of breast cancer and its prognosis. The 2 intervention studies performed so far in women with breast cancer did not provide clear evidence that a reduction in dietary fat intake with or without concomitant increase in fruit, vegetables and fiber improves survival, but had methodological limitations. Thus, further intervention studies are urgently needed to examine the efficacy and safety of lifestyle intervention in 
Table 1. Dietary factors/body weight associated with increased risk of developing postmenopausal breast cancer and poor disease prognosis

\begin{tabular}{|c|c|c|}
\hline \multirow[b]{2}{*}{ Strength of evidence } & \multicolumn{2}{|l|}{ Breast cancer } \\
\hline & Incidence & Prognosis \\
\hline \multirow{2}{*}{ Convincing } & obesity & obesity \\
\hline & alcohol & \\
\hline Probably & weight gain & weight gain \\
\hline Limited/suggestive & total fat & high fat, low fiber \\
\hline \multirow[t]{3}{*}{ Inconclusive } & dietary pattern & dietary pattern \\
\hline & dietary supplements & dietary supplements \\
\hline & & alcohol \\
\hline
\end{tabular}

Data were extracted from the World Cancer Research Fund/American Institute for Cancer Research (WCRF/AICR) report [1], the review by

Pattersson et al. [3], and a literature review by the authors.

women with breast cancer. Such intervention programs should be multimodal, which also includes an increase in physical activity. In view of the significant contribution of body fat mass, it appears justified to aim for moderate weight loss in overweight and obese women.

Until the results of such studies are available, the evidence for dietary recommendations is solely based on the presented literature. As summarized in table 1, a stable normal body weight may have the strongest protective effect against breast cancer, and weight management may also contribute to improved cancer survival. In addition, but less evidence based, a healthy, Mediterranean-type diet may confer some benefit with regard to breast cancer prevention and improvement of prognosis. It is well established that this type of diet significantly reduces the risk of diabetes and cardiovascular disease.

\section{Conflict of Interest}

The authors declare that there is no conflict of interest.

\section{References}

1 World Cancer Research Fund and American Institute for Cancer Research: Food, nutrition, physical activity, and the prevention of cancer: a global perspective. Washington DC, AICR, 2007.

2 Robert Koch-Institut und Gesellschaft für epidemiologische Krebsregister in Deutschland e.V. Krebs in Deutschland 2005/2006. Häufigkeiten und Trends, 7. Ausgabe. Berlin, Robert Koch-Institut, 2010.

3 Patterson RE, Cadmus LA, Emond JA, Pierce JP: Physical activity, diet, adiposity and female breast cancer prognosis: a review of the epidemiologic literature. Maturitas 2010;66:5-15.

4 Brennan SF, Cantwell MM, Cardwell CR, et al.: Dietary patterns and breast cancer risk: a systematic review and meta-analysis. Am J Clin Nutr 2010;91:1294-1302.

5 Trichopoulou A, Bamia C, Lagiou P, Trichopoulos D: Conformity to traditional Mediterranean diet and breast cancer risk in the Greek EPIC cohort. Am J Clin Nutr 2010;92:620-625.

$\checkmark 6$ Cottet V, Touvier M, Fournier A, et al.: Postmenopausal breast cancer risk and dietary patterns in the E3N-EPIC prospective cohort study. Am J Epidemiol 2009;170:1257-1267.

7 Cummings SR, Tice JA, Bauer S, et al.: Prevention of breast cancer in postmenopausal women: approaches of estimating and reducing risk. J Natl Cancer Inst 2009;101:384-398.

8 Brasky TM, Lampe JW, Potter JD, et al.: Speciality supplements and breast cancer risk in the VITamins And Lifestyle (VITAL) cohort. Cancer Epidemiol Biomarkers Prev 2010;19:1696-1708.

$\checkmark 9$ Howe LR: Inflammation and breast cancer. Cyclooxygenase/prostaglandin signalling and breast cancer. Breast Cancer Res 2007;9:210.
10 Key J, Hodgson S, Omar RZ, et al.: Meta-analysis of studies of alcohol and breast cancer with consideration of the methodological issues. Cancer Causes Control 2006;17:759-770.

11 Prentice RL, Caan B, Chlebowski RT, et al.: Lowfat dietary pattern and risk of invasive breast cancer. The Women's Health Initiative randomized controlled dietary modification trial. JAMA 2006; 295:629-642.

12 Kwan ML, Weltzien E, Kushi LH, et al.: Dietary patterns and breast cancer recurrence and survival among women with early-stage breast cancer. J Clin Oncol 2009;27:919-926.

13 Kroenke CH, Fung TT, Hu FB, Holmes MD: Dietary patterns and survival after breast cancer diagnosis. J Clin Oncol 2005;23:9295-9303.

14 Holmes MD, Stampfer MJ, Colditz GA, et al.: Dietary factors and the survival of women with breast carcinoma. Cancer 1999;86:826-835.

15 Greenlee H, Hershman DL, Jacobson JS: Use of antioxidant supplements during breast cancer treatment: a comprehensive review. Breast Cancer Res Treat 2009;115:437-452.

16 Lawenda BD, Kelly KM, Ladas EJ, et al.: Should supplemental antioxidant administration be avoided during chemotherapy and radiation therapy? J Natl Cancer Inst 2008;100:773-783.

17 Shu XO, Zheng Y, Cai H, et al.: Soy food intake and breast cancer survival. JAMA 2009;302:24372443.

18 Ogunleye AA, Xue F, Michels KB: Green tea consumption and breast cancer risk or recurrence: a meta-analysis. Breast Cancer Res Treat 2010; 119:477-484.
19 Chlebowski RT, Blackburn GL, Thomson CA, et al.: Dietary fat reduction and breast cancer outcome: interim efficacy results from the Women's Intervention Nutrition Study. J Natl Cancer Inst 2006;98:1767-1776.

20 Pierce JP, Natarajan L, Caan BJ, et al.: Influence of a diet very high in vegetables, fruit, and fiber and low in fat on prognosis following treatment for breast cancer: the Women's Healthy Eating and Living (WHEL) randomized trial. JAMA 2007;298:289-298.

21 Pierce JP, Natarajan L, Caan BJ, et al.: Dietary change and reduced breast cancer events among women without hot flashes after treatment of early-stage breast cancer: subgroup analysis of the Women's Healthy Eating and Living study. Am J Clin Nutr 2009;89(suppl):1565S-1571S.

22 Protani M, Coory M, Martin JH: Effect of obesity on survival of women with breast cancer: systematic review and meta-analysis. Breast Cancer Res Treat 2010;123:627-635.

23 Calle EE, Kaaks R: Overweight, obesity and cancer: epidemiological evidence and proposed mechanisms. Nat Rev Cancer 2004;4:579-591.

24 Maccio A, Madeddu C, Mantovani G: Adipose tissue as target organ in the treatment of hormonedependent breast cancer: new therapeutic perspectives. Obes Rev 2009;10:660-670.

25 Roberts DL, Dive C, Renehan AG: Biological mechanisms linking obesity and cancer risk: new perspectives. Annu Rev Med 2010;61:301-316. 